\title{
Basta Implementar Inovações nos Sistemas Educativos?
}

Adelson Fernandes Moreira

Centro Federal de Educação Tecnológica - Minas Gerais

\section{Resumo}

Este artigo apresenta referências para melhor compreender a implementação de mudanças na escola, sistematizando-as a partir de um estudo sobre a Reforma do Sistema Educativo na Espanha e a implantação de um Currículo Nacional na Inglaterra e País de Gales, conjugado a revisões de pesquisas desenvolvidas nesse campo. A Reforma do Sistema Educativo espanhol tentou equilibrar o caráter prescritivo de diretrizes gerais com o caráter aberto da atribuição de cada escola elaborar sua proposta curricular, a partir de seu contexto e no marco das diretrizes propostas. Seu estudo contribuiu, sobretudo, para explicitar a diversidade de visões e posicionamentos que emergem do contexto de uma inovação. Essa diversidade é sintetizada na forma de seis diferentes tensões.

A implantação de um Currículo Nacional na Inglaterra objetivou estabelecer um maior controle sobre a escola por intermédio de um currículo detalhado e prescritivo, associado à aplicação de exames externos como instrumentos de avaliação da escola por meio do desempenho dos alunos nos testes. No caso da experiência inglesa, são expostas análises fundadas em um conjunto diversificado de dados de pesquisa. Essas pesquisas apontam resultados desastrosos no contexto escolar, com o empobrecimento da prática pedagógica, predominando atividades preparatórias para os exames externos.

Apresentadas as referências, a partir do substrato proporcionado por essas duas experiências, o autor conclui propondo ir além da perspectiva de implementar inovações em direção a processos de desenvolvimento profissional e institucional, que constituem, na escola, uma maior capacidade de produzir e interagir criticamente com propostas e contextos de mudança.

Correspondência para:

Rua Botelhos, 28 - Bonfim

31210-200 - Belo Horizonte - MG

email:

adelson@cien.deii.cefetmg.br

\section{Palavras-chaves}

Reformas - Reformas Educacionais - Inovações - Inovações Educacionais. 


\title{
Is It Enough To Implement Innovations In Educational Systems?
}

\author{
Adelson Fernandes Moreira \\ Centro Federal de Educação Tecnológica - Minas Gerais
}

Correspondence:

Rua Botelhos, 28 - Bonfim

31210-200 - Belo Horizonte - MG

email:

adelson@cien.deii.cefetmg.br

\section{Abstract}

The paper presents references to better understand the implementation of changes at schools. Systematization of the references is based on a study about the reform of the Spanish education system and the implementation of a national curriculum in England and Wales, as well as on reviews of researches developed in that field. The reform of the Spanish education system attempted to balance the prescriptive character of the general guidelines with the more open approach of leaving each school to elaborate its own curricular proposal (taking into account its social context and the general guidelines). The study of the Spanish reform has contributed mainly to make explicit the diversity of viewpoints and attitudes that emerge within the context of an educational innovation. Such diversity is presented and summarized in the form of six different tensions.

The implementation of the national curriculum in England and Wales aimed to establishing a greater control upon schools through a detailed and prescriptive curriculum, associated to the use of external exams as instruments of evaluating schools by the performance of their students in the exams. In this case, analyses are grounded on various research data. Those studies point to disastrous results in the educational context, with the impoverishment of pedagogical practices where activities targeted at the exams take priority. After using these two experiences to motivate the description of the references, the paper concludes by proposing that we should go beyond implementing innovations, toward processes of professional and institutional development that enable schools to produce proposals and contexts of change, and to interact critically with them.

\section{Key words}

Educational Reforms - Educational Innovations. 


\section{Introdução}

A partir de meados da década de 1980, foram deflagradas, no Brasil, diversas iniciativas de reformulação curricular, algumas abrangendo áreas ou disciplinas, outras de cunho mais geral. Se, por um lado, há uma profusão de iniciativas de reforma, por outro, a maior parte delas é marcada pela descontinuidade. A descontinuidade de políticas subseqüentes leva à repetição de erros e à utilização ineficaz de recursos humanos e materiais, decorrentes, dentre outros fatores, do desconhecimento, da falta de avaliação e análise de experiências precedentes.

Tendo como objeto as inovações educacionais e como foco seu caráter complexo, apresento, neste trabalho, um conjunto de referências para melhor compreender a implementação de mudanças no contexto escolar. Ao sistematizar referências para abordar a implementação de inovações, busco contribuir para o surgimento de trabalhos de pesquisa que focalizem a implementação das mudanças educacionais e os resultados produzidos por elas.

Fullan (1992) argumenta que predominam abordagens fluidas e difusas sobre as políticas de inovação. Tais políticas, na maioria das vezes, são entendidas como intervenções sobre o sistema educativo ou sobre partes dele, ou como iniciativas emergentes do próprio sistema que, de alguma forma "não bem conhecida ou explicada", produzem "determinados" resultados. É necessário levantar dados, analisar, conceituar, buscando elucidar o que efetivamente mudou. É preciso dispor de referências para interpretar resultados e deles extrair lições mais gerais.

Investigando a implantação, podemos começar a identificar os motivos pelos quais e a partir de que ponto de vista as inovações fracassam ou são bem sucedidas. Investigar a implementação de inovações possibilita o contraste entre o currículo real, concretizado na prática de sala de aula, e o formal, registra- do nas propostas escritas. Esse contraste, de acordo com Santos Guerra (1995), possibilita compreender sob que circunstâncias as mudanças curriculares tendem a ocorrer.

Precedendo a apresentação das referências, enuncio as principais contribuições de um estudo sobre a Reforma do Sistema Educativo na Espanha e sobre a implantação de um Currículo Nacional na Inglaterra e País de Gales. Esse estudo possibilitou o contato com diferentes dados e interpretações sobre a implementação daqueles dois programas inovadores, conferindo fundamento às referências propostas. Em seguida, das pesquisas de Fullan $(1992,1993)$ e colaboradores, sistematizo as referências para abordar a implementação de inovações.

Concluo salientando que, ao focalizar a complexidade das inovações, essas passaram a ocupar uma posição secundária, ganhando relevo as estratégias e iniciativas de desenvolvimento profissional e institucional, que buscam criar condições para que os sujeitos, as organizações e sistemas constituam-se como aprendizes capazes de produzir e interagir criticamente com as inovações.

\section{Visões Emergentes do Contexto da Reforma Espanhola}

0 estudo da Reforma do Sistema Educativo na Espanha contribuiu, sobretudo, para explicitar a diversidade de visões e posicionamentos que emergem do contexto de uma inovação. Trabalhei sobre um conjunto de artigos publicados pelo periódico espanhol Cuadernos de Pedagogia, que dedicou amplo espaço à divulgação das diferentes etapas de elaboração e implementação da Reforma, assim como fomentou o debate, possibilitando o contato com diferentes opiniões sobre o processo ocorrido na Espanha. Selecionei artigos publicados durante dez anos, de 1987 a 1997. No ano de 1987, foram apresentadas as diretrizes básicas da 
Reforma, após o desenvolvimento de experiências-piloto em algumas escolas. Os acontecimentos do ano de 1997 sinalizaram o fechamento de um ciclo, dentre eles a chegada ao poder do único partido que havia se contraposto abertamente à Reforma. Os artigos estudados são contribuições de pesquisadores, de professores universitários, de sociólogos, de profissionais envolvidos com a elaboração das diretrizes da reforma e com sua implementação, e de professores e diretores de escola atuando no ensino médio e fundamental. Apresento, a seguir, uma síntese organizada em diferentes tensões constituídas pela diversidade de visões e posicionamentos, no contexto da Reforma.

\section{Os objetivos expressos nos documentos da reforma versus a recepção desses objetivos e sua implementação efetiva na escola}

Essa tensão expressa-se, sobretudo, na afirmação de uma distância e inconsistência entre o discurso das autoridades educativas oficiais e as ações concretas por elas encaminhadas para a implementação da Reforma (Vinao, 1997). Configura-se, também, no sentimento de imposição declarado pelos professores e a atitude de resistência daí decorrente, diante do imperativo de se proceder à mudança das práticas vigentes (Santos Guerra, 1995).

\section{O sistema educativo como espaço de reprodução das desigualdades sociais versus o sistema educativo como espaço de superação das desigualdades sociais}

A Reforma é interpretada a partir das duas perspectivas retratadas no título dessa seção. Os autores que se enquadram na segunda perspectiva não atribuem ao sistema educativo a capacidade e a tarefa exclusivas de superar a desigualdade, mas afirmam que se trata de um espaço fundamental para reduzi-la e contribuir para sua superação. Apresentam como estratégias fundamentais aquelas propostas pela Re- forma: ampliação e universalização do tempo de escolarização básica, dentro de uma perspectiva de formação geral do educando, que reconheça e trabalhe as diferenças, que valorize os processos de socialização e formação do educando como um todo, além da dimensão cognitiva (Nieda, 1990) (Pérez Gomez, 1990).

Quem se insere na primeira perspectiva afirma que o sistema educativo dispõe de mecanismos diferenciados, consolidados lentamente na cultura escolar, para reproduzir a diferença, não obstante os esforços em ampliar e universalizar o período de educação básica, e os esforços para a estruturação e desenvolvimento de currículos flexíveis que possibilitem uma aprendizagem mais contextualizada e o reconhecimento e o trabalho das diferenças entre os alunos. Os defensores desse ponto de vista entendem que as reformas propostas nessa perspectiva são ritos recorrentes, incapazes de produzir as mudanças preconizadas (Enguita, 1989).

\section{Educação geral, básica, para todos versus educação propedêutica, seletiva}

A Reforma fundamentou-se na defesa de uma educação geral, básica, para todos, questionando a precoce divisão dos alunos, aos 14 anos, entre aqueles, com melhor desempenho acadêmico, que teriam a oportunidade de se preparar e fazer um curso universitário, e os alunos a quem se atribuiu desempenho insatisfatório. A esses últimos, caso quisessem continuar estudando, restaria a opção de ingressar em cursos de nível médio de caráter profissionalizante.

Ao ampliar a escolarização obrigatória até os 16 anos, determinando, nesse período, uma formação geral, básica para todos os alunos, sem segregações prematuras, as diretrizes da reforma confrontaram-se com outra visão presente na escola: aquela retratada por Moreno et al. (1994), baseada na concepção de aprendizagem como resultado, sobretudo, do esforço pessoal, que deve ser estimulado e 
reforçado por um ambiente de competição, que reconheça e premie os de melhor desempenho. De acordo com essa visão, a função da educação básica é identificar e preparar os alunos conforme suas capacidades, seja para a carreira universitária, seja para a formação profissional de nível médio.

A primeira visão está em sintonia com um sistema educativo inclusivo, que contribui para superar as desigualdades sociais. A segunda visão articula-se com um sistema educativo seletivo, de caráter excludente, que reproduz e reforça as diferenças e desigualdades sociais.

\section{Modelo de desenvolvimento curricular centro periferia versus modelo de desenvolvimento curricular contextualizado na escola}

Encontrei posicionamentos que interpretam o modelo de desenvolvimento curricular da Reforma como do tipo centro periferia (Santos Guerra, 1995), cabendo ao professor o papel de executar e concretizar propostas não construídas por ele, mas por especialistas e profissionais distantes do contexto e das dificuldades cotidianas da escola. Outros, como Coll (1989), vêem o modelo da Reforma atribuindo protagonismo à escola e ao professor, chamados a elaborar, a partir de diretrizes gerais, um projeto curricular em sintonia com os problemas e as questões próprias da comunidade escolar e da realidade que a envolve.

Essa tensão expressou-se, também, nos desafios relacionados ao desenvolvimento profissional no contexto de uma inovação. Especificamente, no caso espanhol, as necessidades formativas surgidas demandaram um vigoroso programa de capacitação, na medida em que os profissionais da escola foram convocados a elaborar propostas curriculares no marco de diretrizes que implicavam mudanças substantivas no contexto escolar. Os depoimentos estudados afirmam uma incapacidade das autoridades educativas oficiais em desenvolver programas de asses- soria e capacitação suficientemente eficazes para atender ao enorme volume de demandas formativas apresentadas pelos professores.

\section{Autonomia versus controle}

A tensão entre modelos de desenvolvimento curricular está diretamente ligada a outra: a tensão entre autonomia e controle. Em que medida um currículo deve ser prescritivo? Qual o papel e o sentido de propor diretrizes à escola? Como trabalhar com a heterogeneidade de propostas, no caso de uma opção totalmente aberta, no caso do exercício da autonomia escolar sem limites claramente definidos? A tensão entre autonomia e controle é emblemática na experiência espanhola, uma vez que a Reforma tenta equilibrar o caráter prescritivo de suas diretrizes gerais com o caráter aberto expresso pela atribuição a cada escola da tarefa de elaborar sua proposta curricular, a partir de seu contexto e no marco das diretrizes propostas.

No caso espanhol, a visão que pareceu predominar nas escolas é a do desequilíbrio, da primazia do controle exercido pelas diretrizes gerais, pelo grau de inovação e de conflito com a cultura escolar que implicaram, pelo seu excessivo detalhamento, deixando pouco espaço para o exercício da autonomia no contexto da escola (Hernández e Sancho, 1993; Santos Guerra, 1995).

\section{Enfoque disciplinar da área de ciências versus abordagem Integrada da área de ciências}

No âmbito específico da área de ciências, existiu, ao longo da elaboração e implementação da reforma, um intenso debate sobre as opções entre o desenvolvimento dos conteúdos da área a partir de suas disciplinas e uma abordagem integrada das ciências. Os autores favoráveis à abordagem integrada questionam a fragmentação disciplinar, a distância entre os princípios científicos ensinados e a realidade vivida pela aluno. Questionam, também, o 
aprofundamento desnecessário de determinados tópicos, considerando os objetivos de uma educação básica. Defendem uma abordagem integrada, entendendo que essa é a aproximação mais adequada para um enfoque "globalizador", que articule a contribuição de cada disciplina para a compreensão de problemas e situações concretas que tenham significado para o aluno e possibilitem incorporar suas contribuições (Jiménez et al., 1991; Del Carmen, 1994).

Os defensores de um enfoque disciplinar afirmam que ele não é incompatível com uma aprendizagem contextualizada nem com uma visão mais globalizada do conhecimento. Acrescentam que o enfoque disciplinar possibilita uma apropriação pelo aluno, de forma mais consistente, dos princípios científicos, assim como de sua evolução ao longo da história da ciência. Atribuem à abordagem integrada uma visão utilitarista do conhecimento científico e questionam a possibilidade de se desenvolver os conteúdos básicos das diferentes disciplinas da área de ciências, tendo sempre como ponto de partida problemas concretos, próximos da vivência do aluno (Martínez Torregrosa, 1994).

Nieda (1990) salienta que o desenho de área contrapõe-se à formação fundamentalmente disciplinar do professor, predominante no sistema espanhol. Confronta-se, também, com considerações, amplamente discutidas, de que uma abordagem global, no estudo de determinado aspecto da realidade, conduz forçosamente a um estudo superficial. Segundo essa autora, a relação entre global/superficial e disciplinar/científico presta-se a múltiplas discussões, que não se podem solucionar de pronto. Deveriam, por isso, ser objeto de muita reflexão no período de debate sobre a Reforma.

\section{A Implantação de um Currículo Nacional na Inglaterra e no País de Gales}

A experiência inglesa, iniciada em meados de 1987, demonstra como os embates polí- ticos protagonizados por grupos de pressão formadores de opinião, por políticos e profissionais envolvidos na gestão de um programa inovador têm um peso considerável na definição das diretrizes e, especialmente, na sua concretização, muitas vezes bastante distantes dos objetivos iniciais preconizados. Disputas de poder e tomada de decisões coerentes ora com uma, ora com outra corrente ideológica tornaram o processo instável, cheio de idas e vindas, sinalizando, para os profissionais da escola, fragmentação, dispersão, desarticulação entre os responsáveis pela condução da reforma.

A implantação de um Currículo Nacional na Inglaterra objetivou estabelecer um maior controle sobre a escola por meio de um currículo detalhado e prescritivo associado à aplicação de exames externos como instrumentos de avaliação da escola pelo desempenho dos alunos nos testes. No caso da experiência inglesa, contamos com análises sobre dados de implementação, levantados em estudos de caso, entrevistas semi-estruturadas e surveys (Black, 1995; Jenkins, 1995a, 1995b). Essas pesquisas apontam resultados desastrosos no contexto escolar, com o empobrecimento da prática pedagógica, predominando atividades preparatórias para os exames externos.

Se as práticas de avaliação formativa já não eram muito difundidas entre os professores, com a implantação do Currículo Nacional, tornaram-se ainda mais escassas. Difundiu-se entre os professores um sentimento de desvalorização profissional e houve uma forte reação a todo processo, obrigando as autoridades educativas a revisões consecutivas do currículo e do formato dos exames, gerando ainda mais confusão e ceticismo no meio escolar.

$\mathrm{Na}$ experiência inglesa, fica evidente, também, a tensão entre autonomia e controle, quando se tentam produzir mudanças na escola. Nesse caso, as conseqüências negativas resultantes do fortalecimento de apenas 
um dos pólos, no caso um forte controle sobre as escolas.

A aplicação de exames externos associados a uma proposta curricular, que determinou o que ensinar dentro de uma seqüência predeterminada, conduziu ao debate sobre os significados desses exames para a formação do aluno. 0 que, efetivamente, indicam os resultados dos exames externos, quando contrastamos o caráter contextualizado da aprendizagem com testes que primam pela "descontextuação”, visto que têm de apresentar como resultado medidas passíveis de comparação entre o desempenho de diversos alunos? Quais os efeitos na formação dos alunos de um currículo que exclui os valores em benefício da objetividade necessária a esses exames? Elliot (1992), ao debater essas questões, afirma que essa forma de estruturar o currículo, não explicitando a formação de valores, associando-o a exames externos objetivos, que comparam escolas a partir do desempenho dos alunos, expressa a aplicação do modelo de mercado à educação. A educação é um produto a ser adquirido pelos pais, vistos como consumidores. A qualidade do produto expressa-se pelo resultado dos exames, imperando uma visão técnica e restrita do conhecimento e de sua aquisição pelo aluno.

\section{Abordar a Complexidade do Sistema Educativo}

0 estudo das reformas inglesa e espanhola permitiu, portanto, o diálogo com diferentes visões, algumas frutos de posicionamento em um contexto de debate, outras fundadas na análise de dados de pesquisas. Essas duas reformas, de características bastante distintas quanto aos objetivos propostos e estratégia de implantação, se aproximam quando comparamos a recepção feita na escola: a resistência do professorado a prescrições, entendimentos diferenciados e antagônicos sobre os objetivos reais das mudanças propostas e das estratégias encaminhadas para atingi-los. Essas duas experiências atestam, sobretudo, o caráter complexo de uma inovação educacional. São muitos os fatores interligados. A modificação em um deles pode determinar uma alteração de todo o quadro do processo de mudança. São múltiplos os significados atribuídos pelos sujeitos envolvidos em uma inovação. A participação, o engajamento, as ações de oposição sistemática, de indiferença ou mesmo de camuflagem das práticas, para demonstrar apenas uma mudança aparente, estão estreitamente relacionadas com os significados atribuídos. E estes significados estão relacionados aos benefícios que a inovação pode trazer, do ponto de vista dos sujeitos chamados a participar. A cultura instituída e expressa pelas práticas cotidianas não pode ser modificada com ações de curto prazo, com restruturações bruscas e abrangentes, que, muitas vezes, produzem apenas movimento e confusão, mas poucas mudanças substantivas (Sacristán, 1992, 1998). Inovar, no contexto da escola, é, portanto, bastante complexo. Causa e efeito não guardam uma relação linear, seja no espaço, seja no tempo.

Ao estudar as reformas inglesa e espanhola, fui acumulando um conjunto variado de "contra-palavras" que deram maior significado à leitura das contribuições de Fullan (1992, 1993). Este aborda a produção de mudanças no contexto escolar, focalizando seu caráter complexo. Os eixos que apresento a seguir são o resultado das revisões desenvolvidas por esse autor no campo das pesquisas sobre implementação de inovações.

\section{Superar a perspectiva do controle}

Assumir o caráter complexo de uma inovação é, antes de tudo, perder a ilusão do controle. São inúmeros os fatores envolvidos, estando todos interligados. A modificação de um deles pode se dar à revelia da equipe responsável pela gestão do processo. Por exemplo, uma greve de professores; a explosão de demanda por matrícula em determinada 
região, forçando o aumento do número de alunos em sala; um crescimento desordenado do número de escolas, levando à falta de professores; rotatividade nas equipes docentes de cada escola, ou mesmo nas equipes de coordenação e direção nos âmbitos da escola, da gestão política da inovação ou da formação de professores. Um planejamento cuidadoso, que busque fazer previsões minuciosas e esgotar todas as possibilidades, terminará revelando-se exaustivo e insuficiente.

Não é possivel forçar os profissionais e a escola a uma postura efetivamente importante: engajamento, comprometimento, trabalho criativo, atitudes fundamentais para que uma inovação se consolide. Tais atitudes não podem ser prescritas ou controladas. A experiência espanhola nesse sentido é exemplar. 0 desenvolvimento curricular proposto tentou compatibilizar um nível de prescrição, pretensamente geral, com uma grande abertura, para que a escola construísse sua proposta curricular. Entretanto, as diretrizes gerais prescritas à escola determinaram mudanças substantivas que não podiam ser produzidas por mandatos legais. Não se determina que um currículo seja aberto por decreto (Muñoz Escudero, 1990). Não se pode forçar a equipe de uma escola ao nível de engajamento necessário para a elaboração de uma proposta curricular consistente, em sintonia com a realidade, com as necessidades dos alunos e da comunidade que envolve a escola. Devemos, ainda, levar em conta uma possível ausência das competências necessárias para tal empreendimento. Considerando esses fatores, existe uma grande chance de que o projeto curricular elaborado seja apenas uma peça burocrática para satisfazer um mandato legal, mas bastante distante da prática cotidiana da escola.

A tentativa na Inglaterra de se estabelecer um controle rígido produziu uma reação mais contundente. Os professores decidiram boicotar os testes externos. Resistiram de formas diferenciadas, forçando revisões consecutivas, que resultaram o afrouxamento do controle.

\section{A mudança é uma jornada cujo mapa não se conhece antecipadamente}

Reconhecer que não é possível controlar a implementação de uma inovação implica abrir mão de pontos de chegada fixos. Isto não significa ausência de direções claras, objetivos claros e definidos, de planos, de análise racional, coordenação, organização. Contudo, as direções devem ser suficientemente amplas, possibilitando a flexibilidade, a capacidade de negociar permanentemente, sobretudo, com os profissionais da escola. É preciso uma atitude de indagação sistemática sobre os acontecimentos que vão concretizando a implementação. Uma atitude de indagação que permita aprender continuamente com os novos contextos.

\section{Os problemas são inerentes a qualquer contexto de mudança}

Problemas são inerentes a qualquer esforço sério de produzir mudanças. São condição necessária para o aprender. Mas, para tanto, é também essencial uma atitude sistemática de indagação no enfrentamento dos problemas. Não há como desenvolver respostas efetivas a situações complexas, evitando o confronto com os problemas ou mesmo atribuindo-os à resistência, à ignorância e à visão errada de outros. É preciso, ao contrário, tratá-los com profundidade, e, nesta imersão, criar condições para a elaboração de soluções criativas.

A ausência de problemas é, quase sempre, sinal de pouca mudança. Especialmente, a implementação inicial de uma inovação, que ocorra de modo suave, sem conflitos, provavelmente indica uma "trivialização", um rebaixamento de objetivos (Huberman, 1992). Mudanças substantivas envolvem processos complexos. Esses são intrinsecamente ricos em problemas. Um espírito de abertura e de indagação sistemática é essencial na superação das dificuldades. Mudar é, antes de tudo, aprender com os novos contextos. 
Visão e planejamento estratégicos constituem o processo

Se trabalharmos com a perspectiva de que a mudança é um processo, que não devemos trabalhar com pontos de chegada fixos, isto significa que a visão que traduz uma inovação e as ações sistemáticas que a concretizam devem se fazer ao longo da caminhada. Para que seja possível incorporar a contribuição do maior número possivel de profissionais, para que a visão que traduz uma inovação seja resultado do compartilhamento de significados entre os vários profissionais chamados a participar, sobretudo, os que atuam na escola. Para conquistar o engajamento do professor é necessário que ele se reconheça de alguma forma nos elementos que configuram uma inovação.

Consideremos as seguintes situações: uma proposta curricular é apresentada a uma escola, elaborada por profissionais que representam o conjunto de professores; apresenta-se à escola um conjunto de diretrizes bem estabelecidas e articuladas, e os profissionais são chamados ou convocados a compor a proposta curricular que dará concretude às diretrizes. Em ambos os casos, a visão já está dada. Dificilmente será conseguido um engajamento efetivo dos profissionais, não obstante os encontros de debate, de discussão, de esclarecimento, de convencimento sobre a proposta, não obstante os cursos de capacitação e formação. Nessa perspectiva, o desenvolvimento profissional fica atrelado à inovação, adquirindo um caráter utilitário. Não é possível colocar todos a bordo, no início da implementação de uma inovação. Se assumirmos a construção compartilhada da visão que traduz a inovação, isto implica tratar o processo como algo que se desenrolará em longo prazo e que, portanto, deverá contar com uma adesão progressiva das escolas.

\section{Valorizar e articular trabalho individual e trabalho coletivo}

Ao propor esse eixo, quero chamar atenção para o fato de que nem todo trabalho indi- vidual significa isolamento, resistência a aprender o novo, e que nem todo trabalho coletivo significa avanço no interior da escola. A consolidação de culturas de trabalho coletivo requer a existência de profissionais com forte sentido de ação individual, com capacidade de pensar, produzir, atuar de forma autônoma. Nessa perspectiva, o trabalho individual contribui para um trabalho de equipe que torne a escola uma instituição capaz de aprender com e produzir o novo.

Hargreaves (1991) analisa o trabalho cooperativo em relação a quatro tipos de cultura escolar: individualismo fragmentado, balcanização, cooperação formalizada e culturas colaborativas. 0 individualismo fragmentado é a forma tradicional de isolamento do professor. A balcanização, freqüentemente encontrada em escolas de ensino secundário, consiste em subgrupos operando como subentidades separadas, quase sempre em conflito, especialmente em processos de tomada de decisões importantes.

A cooperação formalizada é caracterizada por um conjunto de procedimentos burocráticos, específicos, formais. Muitas iniciativas, tais como programas de tutoria, planejamento conjunto, encontros de professores, programas de formação, nos quais o professor é solicitado ou convocado a participar, situam-se nessa tipologia. Esse tipo pode ignorar a cultura real da escola e levar a uma proliferação de contatos não desejados entre os professores, consumindo o tempo já escasso e produzindo poucos resultados.

Hargreaves e Dawe (1989), aprofundando a reflexão sobre essa cooperação forçada, afirmam que a quebra do isolamento profissional do professor está ligada a um conflito envolvendo duas formas de cooperação. De um lado, a cooperação constitui um instrumento de valorização e crescimento profissional, possibilitando o compartilhamento de experiências entre colegas, em um contexto de reflexão sobre a prática, levando a uma 
ação mais sábia e competente. De outro lado, a quebra do isolamento do professor pode constituir um mecanismo utilizado para facilitar a adoção, sem conflitos e acrítica, de determinadas formas de ação, conjunturalmente, preferidas. Novos estilos de ensinar são introduzidos e impostos por especialistas, por meio de processos nos quais o professor é tratado como um executor, em vez de um profissional capaz de exercer seu juízo crítico.

Culturas colaborativas bem consolidadas têm profundidade, são pessoais e duradouras. Não se formam, simplesmente, no bojo da implantação de projetos ou eventos específicos, dentro de uma visão utilitária do desenvolvimento profissional. Culturas colaborativas, quando existem, são constitutivas, são absolutamente centrais na prática docente cotidiana e não negam o valor dos pontos de vista e do trabalho individuais.

Portanto, culturas fortemente compartilhadas ou culturas individualistas são, ambas, indesejáveis, pois criam contornos, respectivamente, muito rígidos ou inapropriadamente frouxos. Quando o futuro é desconhecido e o contexto que envolve uma instituição modifica-se continuamente de formas imprevisíveis, fontes de diversidade são importantes, assim como situações de convergência. Como afirmado anteriormente, o conflito, se tratado de forma apropriada, é essencial à produção efetiva de mudanças.

Portanto, é preciso aprender a administrar a tensão emergente desses dois pólos: o individual e o coletivo. Não excluir nenhum deles, inseri-los em uma mesma totalidade que contribua para tornar a escola uma instituição aberta, capaz de produzir e interagir com novos contextos.

\section{Nem centralização, nem descentralização}

A tensão entre autonomia da escola e controle externo sobre os processos que nela se desenvolvem foi um dado evidente nas experiências inglesa e espanhola. Mais uma vez tra- ta-se de reconhecer a tensão entre dois pólos, sem excluí-los. Por um lado, favorecer a centralização, com um reforço do controle externo, mediante currículos prescritivos e exames externos, resulta no empobrecimento das práticas no interior da escola, na desvalorização da profissão docente, no predomínio de propostas técnicas, que excluem a discussão sobre valores e transformam a educação em mercadoria.

Por outro lado, a autonomia dentro de uma política amplamente descentralizada não garante o avanço da escola. Se a escola consegue propor e realizar inovações, essas não perduram durante muito tempo sem o apoio político e institucional necessário, sem a possibilidade de interlocução com agentes externos que realimentem e fortaleçam o processo. A escola pode, em outra perspectiva, fechar-se em práticas conservadoras ou acomodar-se no convívio com problemas que são atribuídos a outros agentes e espaços sociais. A tensão entre autonomia e controle, entre centralização e descentralização, é necessária. A escola precisa ser pressionada a rever continuamente suas práticas e dispor da autonomia necessária para a construção de projetos que traduzam as possibilidades de seu grupo de profissionais em cada momento. 0 poder público deve exercer pressão, mas, ao mesmo tempo, oferecer o suporte necessário para que os professores avancem a partir do ponto em que se encontram. Nem centralização, nem descentralização. Trata-se de perseguir o difícil equilíbrio entre autonomia e controle, entre pressão e suporte.

\section{É essencial conectar-se ao contexto mais geral}

A produção de mudanças no interior da escola passa pela abertura da instituição, passa pela atitude de transpor seus muros, abrir portas e janelas. Significa reconhecer que os desafios apresentados à escola não serão vencidos apenas pelos profissionais que atuam 
dentro dela. É fundamental estimular a abertura da escola à participação dos diferentes segmentos sociais. Este é um movimento que gera grande insegurança e resistência no interior da escola. Por isso, reforço a perspectiva da mudança como um processo, com ações de longo prazo, que contribuam para o desenvolvimento da instituição e de seus profissionais, de forma que ela vá construindo competências para esse diálogo com outros segmentos e outras instituições, que reivindicam interferir e participar mais na definição dos rumos da escola. A construção de currículos e de uma prática escolar, dentro de uma perspectiva emancipatória, passa, necessariamente, pela abertura e não fechamento da escola.

\section{Reconhecer a história profissional do professor}

Sem perder de vista a importância do equilíbrio entre o individual e o coletivo, esse eixo aponta no sentido de reconhecer a história profissional do professor e de como ela determina seu nível de engajamento em uma inovação. Esse eixo aponta na direção de resgatar os fatores que motivaram o docente a optar por essa profissão e que se vão arrefecendo com o passar do tempo, diante de sucessivos fracassos, diante do isolamento profissional, da pesada jornada de trabalho, dos baixos salários.

Diferentes experiências, que buscaram mudanças, seja no campo das políticas de intensificação com a ampliação do controle sobre a escola, seja no campo das políticas de reestruturação com ênfase em uma gestão descentralizada, não implicaram modificações nas crenças, nas habilidades e competências dos professores, e, portanto, nas práticas instituídas. Mudanças na estrutura não implicam, necessariamente, ruptura com a cultura escolar.

Mudar visões sobre a função social da escola, sobre como o aluno aprende, e constituir novas competências e habilidades têm como condição primeira comprometer o professor com o processo. Implica resgatar e fortalecer seu pro- pósito pessoal no exercício da profissão. Não é tarefa fácil, considerando as condições de trabalho docente e de valorização profissional, mas é um elemento fundamental na composição de uma política de desenvolvimento profissional e institucional, para além deste ou daquele programa pretensamente inovador.

\section{Conclusão: Ultrapassar a Perspectiva da Implementação de Inovações}

Os eixos que apresentei se articulam em torno de três importantes mensagens: o caráter complexo das inovações; a impossibilidade de controle e a visão da mudança como um processo; e a necessidade de superar o caráter utilitário das políticas de desenvolvimento profissional e institucional atreladas e utilizadas como instrumentos de concretização de inovações, estas sempre cambiantes, na medida em que são resultado de como os governantes de turno interpretam as demandas sociais sobre a escola.

Diante de tanta complexidade, incertezas e variáveis de todos os tipos, sobre as quais é impossivel estabelecer controle, o estudo sobre a implementação de inovações conduziu à sua ultrapassagem. Proponho, portanto, deslocar o foco da implementação de inovações, mais localizadas ou mais abrangentes, para a necessidade de criar uma maior capacidade institucional de inovar. Focalizar o desenvolvimento institucional, objetivando que as escolas e os órgãos oficiais locais adquiram competências para diagnosticar problemas e encaminhar com autonomia as soluções, para interagir seletivamente com as inovações, com os meios e recursos de que se dispõe, para criar espaços e procedimentos de desenvolvimento profissional permanentes. Dito de forma geral, capacitarem-se para produzir e gerenciar contextos de mudança, de forma crítica e com a mesma desenvoltura com que se convive com momentos de estabilidade. 
Pensando no contexto brasileiro, uma justificativa para a focalização do desenvolvimento da instituição escola, indo além da concretização de reformas mais ou menos abrangentes, é a própria descontinuidade das políticas públicas. A produção de mudanças no sistema educativo, considerando sua complexidade e os oito eixos de abordagem apresentados, implica ações sistemáticas, contínuas, de longa duração. Programas de inovação bem sucedidos, relatados por Fullan (1992, 1993), demandaram mais de uma década de ações coordenadas, envolvendo uma forte parceria entre escola, instância governamental local e universidade. Foram atendidas condições, como continuidade, tempo para que as visões fossem constituídas e compartilhadas. Demanda tempo para que as mudanças efetivamente se façam na estrutura e nas práticas das instituições participantes do processo, e interfiram, finalmente, na formação, aprendizagem e desenvolvimento de professores e alunos, no âmbito da escola e da universidade.

A necessidade de ações sistemáticas de longo prazo choca-se com a descontinuidade das políticas públicas. Dentre os inúmeros fatores concorrentes para essa descontinuidade, destacamos a perspectiva sempre iminente de mudanças radicais, a cada quatro anos, com as eleições. Porque, circunstancialmente, a formulação e implementação de determinada política estarão sujeitas ao acidente de percurso eleitoral. Não defendo abrir mão de diretrizes que traduzam um projeto de educação, que cumpram o papel de sintonizar a escola com as demandas sociais de seu tempo. No entanto, a interpretação hegemônica dessas demandas e as diretrizes decorrentes são contingentes e subordinadas a projetos mais amplos, expressões das forças políticas que exercem o governo de turno.

Em meio a essa conjuntura sempre instável, especialmente em nosso país, a escola sobrevive. E, nesse processo, pode ir fortalecendo-se ou enfraquecendo-se como instituição. Considerando os eixos apresentados, afirmo que uma política pública em educação deve ter como um de seus pilares, não o único, o desenvolvimento institucional da escola. Não subordinado, mas conjugado à produção de inovações, e que tenha como elemento fundamental o desenvolvimento dos profissionais que nela trabalham, a constituição da capacidade de produzir e lidar com o novo.

No campo do desenvolvimento profissional, saliento a necessidade de se resgatar e estimular o desenvolvimento de um propósito pessoal, que motive e mobilize as potencialidades do sujeito no exercício da profissão. Resgatar essa motivação interior do sujeito não significa fechamento às questões sociais e projetos mais amplos. Significa criar bases para superar uma atitude de alienação e estimular o engajamento, com identidade, na construção de culturas de trabalho colaborativo dentro da escola. Hernández e Sancho (1993) afirmam que, na relação entre a inovação e as pessoas, na realidade subjetiva implicada no contexto individual e organizativo de cada um, se situa a pedra angular da problemática da mudança.

Fullan (1993) salienta os inúmeros casos, documentados em pesquisa, de profissionais que ingressaram na carreira com grande motivação em atuar na formação e desenvolvimento dos alunos, em contribuir para a construção de uma sociedade mais justa, e que, paulatinamente, vão assumindo uma atitude cínica, alienada, indiferente diante do exercício profissional. Essa deterioração do exercício profissional relaciona-se fortemente ao sentimento de fracasso, de incapacidade de efetivamente interferir, de fazer diferença, seja no âmbito da sala de aula, seja em relação a projetos de sociedade mais amplos. As reformas, por seu turno, ao fracassarem na produção de resultados diretamente ligados ao ensino e aprendizagem dos alunos, indo e vindo, com abordagens superficiais, fragmentadas e descontínuas, contribuem, em igual medida, desencorajando o conjunto dos 
docentes, inclusive aqueles com maior disposição e comprometimento.

Essa retomada e (re)construção do propósito pessoal devem estar articuladas a iniciativas que favoreçam a formação de uma atitude de indagação sistemática. Devem, também, possibilitar ao professor a aquisição de competências para compreender com mais profundidade 0 processo de aprendizagem e viabilizar diferentes estratégias de ensino, para lidar com a diversidade de ritmos e de culturas presentes na escola. Trata-se de conceber o desenvolvimento profissional na perspectiva do professor aprendiz como um processo permanente, que engloba o período de formação inicial e toda a carreira.

0 desenvolvimento institucional, em uma linha de reciprocidade, deve se dar na perspectiva da escola, também concebida como uma organização aprendiz. Uma instituição com autonomia para estabelecer novas e diferentes formas de trabalho, de modo a lidar com as dinâmicas forças de mudança. Atuar com o objetivo de desenvolver a instituição é fomentar estruturas flexíveis, com o agrupamento de profissionais que aprendam trabalhando com um maior grau de liberdade, assumindo riscos e extraindo lições de situações abertas. Assumir a não previsibilidade das intervenções no sistema educativo implica não estabelecer objetivos de chegada estáticos.

Numa instituição aprendiz, há espaço para o conflito. Constituí-la significa favorecer a formação de uma comunidade de profissionais sempre abertos a aprender, a buscar a ajuda um do outro, a rever e modificar continuamente suas práticas. Uma instituição aprendiz extrai da tensão emergente da diversi- dade a força de seu próprio desenvolvimento.

Focalizar o desenvolvimento institucional, nessa perspectiva, implica questionar as reformas estruturais que trazem em seu bojo a homogeneização das práticas educativas, o controle a partir da padronização de resultados. Significa colocar em cheque a própria ação de gestar e implementar reformas e programas inovadores. Implica chamar as autoridades educativas oficiais a rever seu papel na elaboração de políticas e diretrizes educacionais. Implica repensar o sentido e o significado de propor diretrizes, tendo em vista a complexidade dinâmica dos sistemas educativos. Se assumirmos que mudança e aprendizagem efetivas ocorrem sempre localmente, qualquer pretensão de exercer o controle "de cima para baixo" é uma ilusão. 0 papel central das autoridades educativas oficiais é o de criar condições para que os sujeitos da comunidade escolar, sobretudo os profissionais que atuam na escola, desenvolvam capacidades básicas de produzir e lidar com as forças da mudança. A questão que deve nortear a estruturação de políticas educacionais é a de como as instituições educacionais, controladas localmente, podem ativar a auto-regulação e a coordenação de suas ações, para consecução de objetivos mais amplos.

Como ponto de partida, aponto o estabelecimento de diretrizes que encaminhem as ações no sentido do desenvolvimento institucional, fundado na concepção do professor e da instituição aprendizes, cujas características básicas foram apresentadas no exercício de sistematizar os eixos, para abordar a complexidade do sistema educativo. 


\section{Referências bibliográficas}

BLACK, P. The struggle to fomulate a national curriculum for science in England and Wales. Studies in Science Education, Leeds, n.26, p.159-188, 1995.

COLL, C. S. Diseño curricular base y proyectos curriculares. Cuadernos de Pedagogía, Barcelona, n.168, p.8-14, mar.1989.

DEL CARMEN, L. Ciencias de la naturaleza: área curricular o suma de disciplinas? Infancia y Aprendizaje, Madrid, n.65, p.7-17, 1994 apud JIMÉNEZ, M. P. A. e PUIG, N. S. The development of a new science curriculum for secondary school in Spain: opportunities for change. International Journal of Science Education,London, v.17, n.4, p.425-439, 1995.

ELLIOTT, J. Una crítica del curriculum nacional británico. Cuadernos de Pedagogia, Barcelona, n.200, p.75-79, fev.1992.

ENGUITA, M. F. Sísifo en la escuela. Los efeitos contraditórios de las reformas del sistema escolar. Cuadernos de pedagogia, Barcelona, n.173, p.60-62, set.1989.

FULLAN, M. Change Forces: probing the deaths of educational reform. London: The Falmer Press, 1993.162p.

FULLAN, M. Successful school improvement. Buckingham: Open University Press, 1992.130p.

HARGREAVES, A.; DAWE, R. Coaching as unreflective practice: contrived collegiality or collaborative culture. In: ANNUAL MEETING OF THE AMERICAN EDUCATIONAL RESEARCH ASSOCIATION, San Francisco, 1989 apud FULLAN, M. Successful school improvement. Buckingham: Open University Press, 1992.130p.

HERNÁNDEZ, F.; SANCHO, J. M. Sueñan los innovadores con realidades galácticas? Cuardernos de Pedagogia, Barcelona, n.214, p.68-70, maio 1993.

HUBERMAN, M. Critical Introduction. In: FULLAN, M. Successful school improvement. Buckingham: Open University Press, 1992. p.1-20.

JENKINS, E. W. Central policy and teacher response? scientific investigation in the national curriculum of England and Wales. International Journal of Science Education, London, v.17, n.4, p.471-480, 1995 a.

JENKINS, E. W. When is a policy not a policy? school-based assessment of practical science at $16^{+}$. International Journal of Science Education, London, v.17, n.5, p.555-563, 1995b.

JIMÉNEZ, M. P. A.; GAYOSO, I. G. R.; BARRAL, F. M. L. Pero, existe el área de ciencias? Cuadernos de Pedagogia, Barcelona, n.188, p.64-66, jan.1991.

MARTÍNEZ TORREGROSA, J. Aprender y enseñar ciencias o cosas de las ciencias? Infancia e Aprendizaje, Madrid, n.65, p.39-43, 1994 apud JIMÉNEZ, M. P. A. e PUIG, N. S. The development of a new science curriculum for secondary school in Spain: opportunities for change. International Journal of Science Education, London, v.17, n.4, p.425-439, 1995.

MORENO, E.; PEDRALS, J.; TORNÉ, R. El milagro de la comprensividad. Cuadernos de Pedagogia, Barcelona, n.230, p.56-57, nov. 1994.

MUÑOZ ESCUDERO, J. M. Dispone la reforma de um modelo teórico? Cuadernos de Pedagogia, Barcelona, n.181, p.88-92, maio 1990.

NIEDA, J. El diseño curricular base. Cuadernos de Pedagogia, Barcelona, n.180, p.8-11, abr. 1990.

PÉREZ GÓMEZ, A. I. La formación del profesor y la reforma educativa. Cuadernos de Pedagogia, Barcelona, n.181, p.84-87, maio 1990. 
SACRISTÁN, J. G. Reformas educativas y reforma del currículo: anotaciones a partir de la experiencia española. In: WARDE, M. J. (Org.) Novas políticas educacionais: críticas e perspectivas. São Paulo: Programa de Pós-Graduados em Educação: História e Filosofia da Educação da Pontifícia Universidade Católica de São Paulo, 1998. p.85-108. dez.1992.

Reformas Educativas. Utopia, retórica e práctica. Cuadernos de Pedagogia, Barcelona, n.209, p.62-68,

SANTOS GUERRA, M. A. El discurso crítico ascendente. Cuadernos de Pedagogía, Barcelona, n.233, p.82-85, fev. 1995.

VIÑAO, A. F. Educación comprensiva: experimento con la utopía. Cuadernos de Pedagogia, Barcelona, n.260, p.10-17, 1997.

Recebido em 17 jul. 1999

Aprovado em 16 nov. 1999 